\title{
Imidazolinium and amidinium salts as Lewis acid organocatalysts
}

\author{
Oksana Sereda ${ }^{1}$, Nicole Clemens ${ }^{1}$, Tatjana Heckel ${ }^{2}$ and René Wilhelm ${ }^{* 1,2}$
}

\section{Full Research Paper}

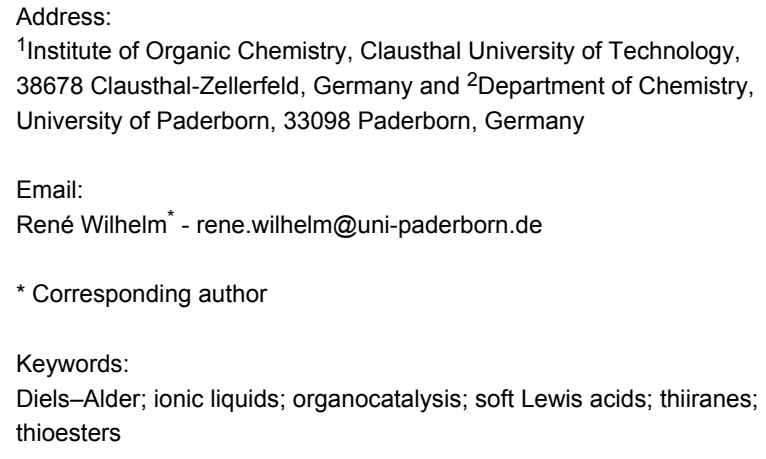

\begin{abstract}
The application of imidazolinium and amidinium salts as soft Lewis acid organocatalysts is described. These salts were suitable catalysts for the activation of unsaturated thioesters in a Diels-Alder reaction and in the ring opening of thiiranes and epoxides. The products were isolated in good yields. The mild catalysts did not cause desulfurization of the products containing a thiol or thiocarbonyl group.
\end{abstract}

\section{Introduction}

Salts with melting points below $100{ }^{\circ} \mathrm{C}$ are known as ionic liquids and are often used as novel solvents for reactions and electrochemical processes [1]. Several of these solvents can contribute to the research field of "green chemistry" [2]. The most common used ionic liquids are based on imidazolium cations. Next to their application in catalytic reactions [3-6], they are also capable of catalyzing reactions themselves, either in substoichiometric amounts or as reaction medium due to hydrogen-bond activation of the protons of the imidazolium cation [7-10] and other variables, such as $\pi$-orbital and charge-charge interactions [8-10].
Recently, we applied saturated imidazolium salts with an aryl substituent at the $\mathrm{C}(2)$ position as catalysts for the azaDiels-Alder reaction [11,12]. These catalysts do not activate the substrate through hydrogen bonding, but instead, like other carbon-cation based catalysts, through their positive center [8-10,13-15], and belong also to the field of organocatalysis $[10,16,17]$.

Taking the soft Lewis acidic character of imidazolinium salts into consideration, we were interested to apply these salts in a Diels-Alder reaction with ethyl crotonthioate as dienophile. 
Due to the low electronegativity of sulfur it would be difficult to catalyze this reaction with hydrogen-bond activation catalysts [18]. The utilization of the soft Lewis basic sulfur groups in this reaction is rare. Often mercury Lewis acids are applied [19-22] to activate the sulfur group and there is also the risk of desulfurization [23].

The only known asymmetric Diels-Alder reaction with ethyl crotonthioate (1) and cyclopentadiene (2) in the presence of optically pure 2,2'-dimercurio-1,1'-binaphthyl compound $\mathbf{3}$ gave the product 4 in $44 \%$ yield with $58 \%$ ee (Scheme 1) [20].

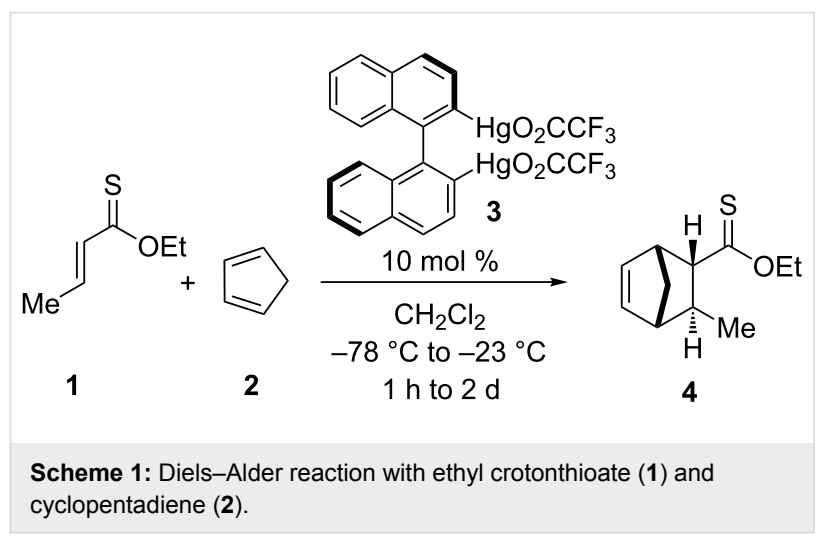

\section{Results and Discussion}

Since product $\mathbf{4}$ has a low boiling point and proved difficult to purify on a small scale, the model reaction shown in Scheme 2 was evaluated. The $\alpha, \beta$-unsaturated thioester 5 was prepared from ethyl cinnamate and 2,4-bis(4-methoxyphenyl)-1,3,2,4dithiadiphosphetane-2,4-disulfide (Lawesson's reagent) [22]. The cycloaddition of ethyl thionocinnamate (5) with 1.5 equiv of cyclopentadiene (2) was performed in different solvents, at varied temperatures, by using a broad range of catalysts, which are summarized in Table 1.

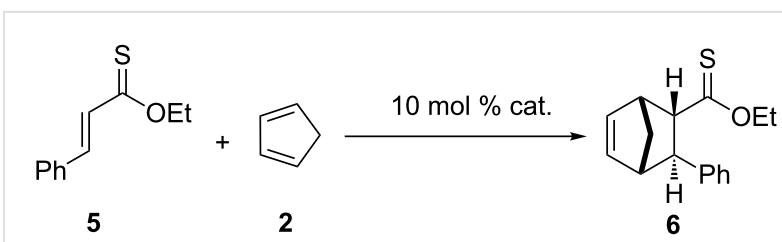<smiles>[NH3+]CC1=C(P)N(Cc2ccccc2)C(c2ccccc2)C1c1ccccc1</smiles>

7<smiles>CC(=O)N1C(c2ccccc2)=C(c2ccccc2)C(c2ccccc2)N1C</smiles>

$\mathrm{NTf}_{2} \ominus$<smiles>CN1C(c2ccc(Cl)cc2)=NC(c2ccccc2)C1c1ccccc1</smiles>
$\mathrm{B}\left[3,5-\left(\mathrm{CF}_{3}\right)_{2}-\mathrm{C}_{6} \mathrm{H}_{3}\right]_{4}^{\ominus}$

9<smiles></smiles>

10

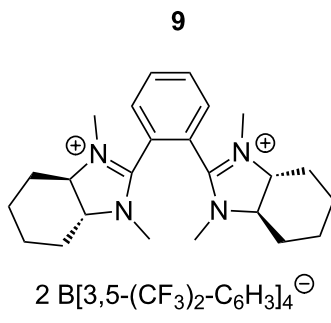

11
Scheme 2: Diels-Alder reaction catalysed with imidazolinium salts.

First a few metal-based Lewis acids were applied in the reaction. $\mathrm{BF}_{3} \cdot \mathrm{Et}_{2} \mathrm{O}$ is known to activate also sulfur carbonyl groups [24] and gave the product in $90 \%$ yield, while TMSOTf gave the product in $55 \%$ yield. In both cases the endo product was the major product. The reaction was followed by TLC and the temperature was gradually increased from -10 to $45{ }^{\circ} \mathrm{C}$ over 4 days in ca. $10^{\circ} \mathrm{C}$ steps.

Next, imidazolinium salt 7 [25] was used in the reaction. The formation of the product was observed at $45{ }^{\circ} \mathrm{C}$; however, the

Table 1: Diels-Alder reaction with $10 \mathrm{~mol} \%$ catalyst according to Scheme 2 . Reactions with $\mathrm{CH}_{2} \mathrm{Cl}_{2}$ were carried out in a pressure vessel.

\begin{tabular}{|c|c|c|c|c|c|}
\hline entry & solvent & catalyst & temp $\left[{ }^{\circ} \mathrm{C}\right]$ & time [d] & yield \%a (endo:exo) \\
\hline 1 & $\mathrm{CH}_{2} \mathrm{Cl}_{2}$ & $\mathrm{Hg}(\mathrm{OAc})_{2}$ & $-10-45$ & 4 & 0 \\
\hline 2 & $\mathrm{CH}_{2} \mathrm{Cl}_{2}$ & $\mathrm{BF}_{3} \cdot \mathrm{Et}_{2} \mathrm{O}$ & $-10-45$ & 4 & $90(99: 1)$ \\
\hline 3 & $\mathrm{CH}_{2} \mathrm{Cl}_{2}$ & TMSOTf & $-10-45$ & 4 & $55(99: 1)$ \\
\hline 4 & $\mathrm{CH}_{2} \mathrm{Cl}_{2}$ & 7 & $25-45$ & 4 & $8(13: 1)$ \\
\hline 5 & toluene & 7 & $25-110$ & 4 & 0 \\
\hline 6 & dioxane & 7 & $25-110$ & 4 & $6(3: 1)$ \\
\hline 7 & $\mathrm{CH}_{2} \mathrm{Cl}_{2}$ & 8 & $25-45$ & 4 & $5(9: 1)$ \\
\hline 8 & $\mathrm{CH}_{2} \mathrm{Cl}_{2}$ & 9 & $0-45$ & 4 & $12(14: 1)$ \\
\hline 9 & $\mathrm{CH}_{2} \mathrm{Cl}_{2}$ & 10 & $-10-45$ & 4 & 69 (99:1) \\
\hline 10 & $\mathrm{CH}_{2} \mathrm{Cl}_{2}$ & 11 & $0-45$ & 3 & $66(99: 1)$ \\
\hline
\end{tabular}

asolated yields. 
product was isolated only in a low yield of $8 \%$. In toluene no reaction was observed even under reflux. In dioxane under reflux a low yield of $6 \%$ was obtained with a low endo/exo ratio of (3:1). Salt 8 [25] and 9 [25] gave similar poor results as salt 7 [25]. Finally, the bis-imidazolinium salt 10 [12] gave the product in $69 \%$ yield with an endo/exo ratio comparable to $\mathrm{BF}_{3} \cdot \mathrm{Et}_{2} \mathrm{O}$. The reaction started slowly at $10^{\circ} \mathrm{C}$. In addition, the similar salt 11 [12] gave the product in a comparable yield of $66 \%$. Although in all cases the product was racemic, the results show that bis-imidazolinium salts can be applied as Lewis acid organocatalysts to activate a thiocarbonyl group.

Next, the behavior of these salts in the ring opening of a thiirane was explored. No activity was observed with salt 9 in the ring opening with aniline. Therefore, the more active bis-imidazolinium salt $\mathbf{1 0}$ was applied with thiirane $\mathbf{1 2}$ and aniline in $\mathrm{CH}_{2} \mathrm{Cl}_{2}$. A yield of $18 \%$ was obtained. However, in the absence of a solvent the yield increased to $98 \%$ after $16 \mathrm{~h}$ (Scheme 3). In the absence of a catalyst a yield of $12 \%$ was obtained under neat conditions. Product 13 was obtained in all reactions as racemate in the error range of the HPLC measurements.

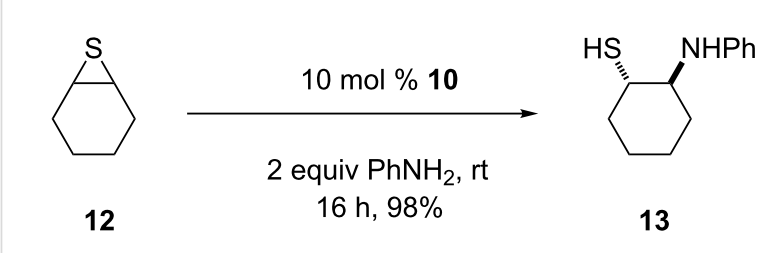

Scheme 3: Ring opening of thiirane 12.

Next, several salts were explored in the ring opening of cyclohexene epoxide with aniline (Scheme 4, Table 2). A reaction in $\mathrm{CH}_{2} \mathrm{Cl}_{2}$ in the absence of the catalyst gave a yield of $10 \%$ after $24 \mathrm{~h}$ (Table 2, entry 1).

The camphor based salt 16 gave a yield of $24 \%$, while bisimidazolinium salt $\mathbf{1 7}$ resulted in a yield of $60 \%$ (Table 2, entries 2 and 3). The bis-imidazolinium salts $\mathbf{1 0}$ and $\mathbf{1 1}$ gave lower yields compared to $\mathbf{1 7}$. However, when the reaction was carried out in the absence of a solvent, the yield increased with salts $\mathbf{1 0}$ and $\mathbf{1 1}$ to 98 and 96\%, respectively (Table 2, entries 6 and 7).

Compared to sulfur, oxygen is a good hydrogen-bond acceptor. Hence, also imidazolinium salts with a $\mathrm{C}(2) \mathrm{H}$ unit were applied in the reaction. Here, an activation of the epoxide can be also possible through hydrogen bonding next to the direct interaction with the positively charged NCN center. While salt $\mathbf{1 8}$ displayed very low catalytic activity, salt $\mathbf{1 9}$ gave the product in $78 \%$ yield (Table 2, entry 10 ). This phenomenon may be

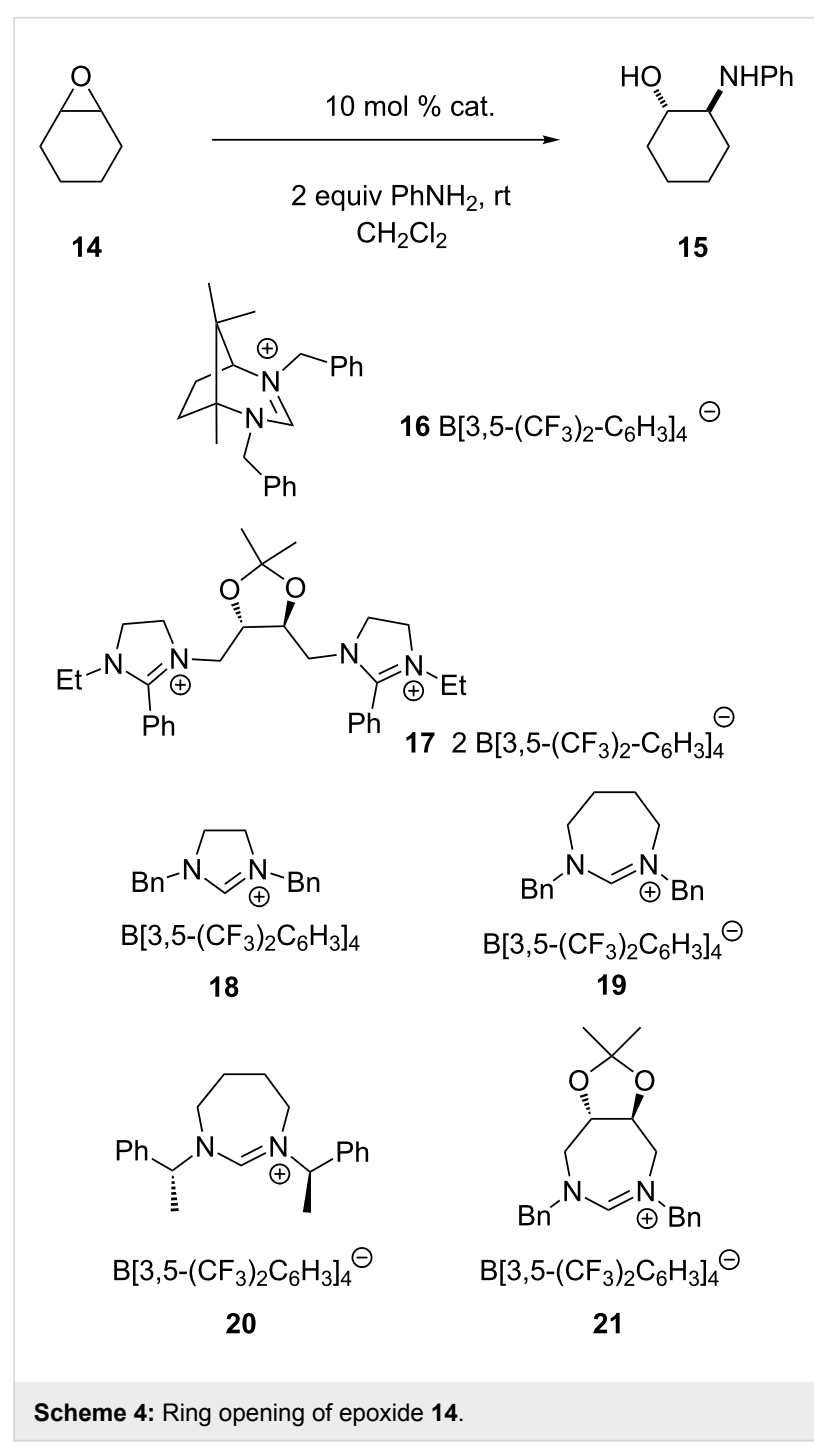

\begin{tabular}{|c|c|c|c|c|}
\hline entry & solvent & catalyst & time & yield $\% a$ \\
\hline 1 & $\mathrm{CH}_{2} \mathrm{Cl}_{2}$ & - & $24 \mathrm{~h}$ & 10 \\
\hline 2 & $\mathrm{CH}_{2} \mathrm{Cl}_{2}$ & 16 & $24 \mathrm{~h}$ & 24 \\
\hline 3 & $\mathrm{CH}_{2} \mathrm{Cl}_{2}$ & 17 & $48 \mathrm{~h}$ & 60 \\
\hline 4 & $\mathrm{CH}_{2} \mathrm{Cl}_{2}$ & 10 & $48 \mathrm{~h}$ & 34 \\
\hline 5 & $\mathrm{CH}_{2} \mathrm{Cl}_{2}$ & 11 & $48 \mathrm{~h}$ & 48 \\
\hline 6 & neat & 10 & $24 \mathrm{~h}$ & 98 \\
\hline 7 & neat & 11 & $24 \mathrm{~h}$ & 96 \\
\hline 8 & neat & - & $24 \mathrm{~h}$ & 0 \\
\hline 9 & $\mathrm{CH}_{2} \mathrm{Cl}_{2}$ & 18 & $48 \mathrm{~h}$ & 12 \\
\hline 10 & $\mathrm{CH}_{2} \mathrm{Cl}_{2}$ & 19 & $24 \mathrm{~h}$ & 78 \\
\hline 11 & $\mathrm{CH}_{2} \mathrm{Cl}_{2}$ & 20 & $24 \mathrm{~h}$ & 38 \\
\hline 12 & $\mathrm{CH}_{2} \mathrm{Cl}_{2}$ & 21 & $6 \mathrm{~h}$ & 99 \\
\hline 13 & toluene & - & $2 \mathrm{~h}$ & 0 \\
\hline 14 & toluene & 21 & $2 \mathrm{~h}$ & 89 \\
\hline
\end{tabular}

alsolated yields. 


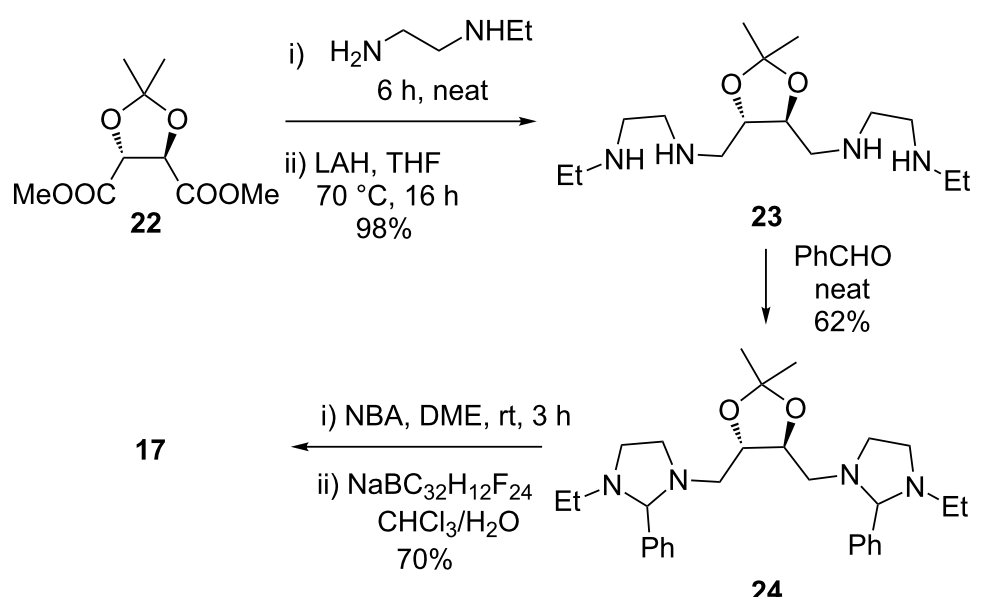

Scheme 5: Synthesis of bis-imidazolium salt 17.

explained by the better delocalization of the positive charge in the planar $\mathrm{sp}^{2}$-centered imidazoline scaffold in salt $\mathbf{1 8}$. Meanwhile the special geometry of 7-membered 1,3-diazepinium cations such as $\mathbf{1 9}$ does not allow the planar conformation to be kept, thus the positive charge is less delocalized over the NCN atoms (Scheme 4) [26-29]. Salt 16, incorporating a sixmembered ring as the smallest ring, displayed a catalytic activity between salt $\mathbf{1 8}$ and $\mathbf{1 9}$. Salt 20, with a larger steric environment around the amidinium unit next to the nitrogen atoms, gave a yield of only $38 \%$ (Table 2 , entry 11 ). On the other hand salt 21 gave the product in $99 \%$ yield after $6 \mathrm{~h}$ (Table 2, entry 12). By changing the solvent from dichloromethane to toluene the reaction time was even further reduced with salt 21, and the product was isolated in $89 \%$ yield (Table 2, entry 14). In all cases product $\mathbf{1 5}$ was racemic in the error range of the HPLC measurements.
Salt 17 was prepared according to Scheme 5. The synthetic route involved a tetraamine formation via amidation under neat conditions and reduction with $\mathrm{LAH}$, furnishing the product in 98\% yield over two steps. Next, the aminal formation under neat conditions was performed. The aminal was further oxidized to a bromide salt by $N$-bromoacetamide in dimethoxyethane. The bromide counter anion was further efficiently replaced by a tetrakis(3,5-bis(trifluoromethyl)phenyl)borate anion providing the salt $\mathbf{1 7}$ by anion metathesis.

The 7-membered 1,3-diazepinium salts were prepared according to Scheme 6. Salts $\mathbf{1 9}$ and $\mathbf{2 0}$ were prepared in a standard way by treatment with triethyl orthoformate in the presence of ammonium tetrafluoroborate followed by anion metathesis in 33 and 29\% yield, respectively.
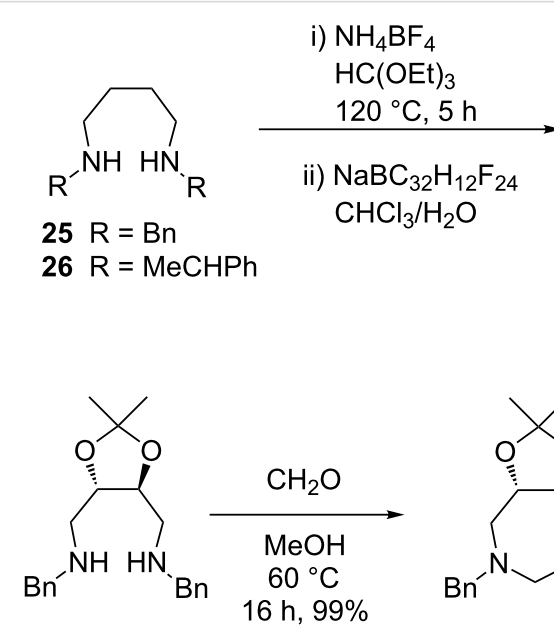

27

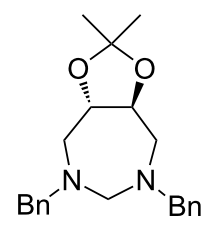

28
$33 \% 19 \mathrm{R}=\mathrm{Bn}$

$29 \% 20 \mathrm{R}=\mathrm{MeCHPh}$

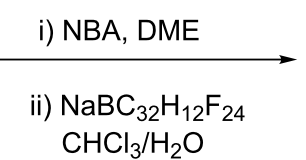

21

$45 \%$

Scheme 6: Synthesis of amidinium salt 21. 
Due to the low yield, salt $\mathbf{2 1}$ was prepared through a different route. First amine 27 [30] was transformed with formaldehyde to the aminal 28. The latter could be oxidized to the corresponding bromide salt, which was transformed directly by anion metathesis to the salt $\mathbf{2 1}$.

\section{Conclusion}

It was possible to prepare new metal-free Lewis acids containing bis-imidazolinium cations and investigate the salts as organocatalysts. Although with enantiopure chiral salts no enantiomeric excess was observed, it was shown for the first time that these salts can interact with thiocarbonyl groups and thiiranes in order to activate these substrates. In addition, it was found that 7-membered 1,3-diazepinium cations are good catalysts for the ring opening of epoxides and that these salts are more reactive than imidazolinium salts.

\section{Supporting Information}

\section{Supporting Information File 1}

Experimental part.

[http://www.beilstein-journals.org/bjoc/content/ supplementary/1860-5397-8-205-S1.pdf]

\section{Acknowledgements}

Financial support by the DFG is gratefully acknowledged. In addition, Dr. Dräger from the University of Hannover is acknowledged for HRMS measurements.

\section{References}

1. Wasserscheid, P.; Welton, T., Eds. Ionic Liquids in Synthesis, 2nd ed.; Wiley-VCH: Weinheim, Germany, 2008; Vol. 1-2.

2. Rogers, R. D.; Seddon, K. R., Eds. Ionic Liquids as Green Solvents: Progress and Prospects; American Chemical Society: Washington, DC, 2003.

3. Zhao, D.; Wu, M.; Kou, Y.; Min, E. Catal. Today 2002, 74, 157. doi:10.1016/S0920-5861(01)00541-7

4. Baudequin, C.; Baudoux, J.; Levillain, J.; Cahard, D.; Gaumont, A.-C.; Plaquevent, J.-C. Tetrahedron: Asymmetry 2003, 14, 3081. doi:10.1016/S0957-4166(03)00596-2

5. Jain, N.; Kumar, A.; Chauhan, S.; Chauhan, S. M. S. Tetrahedron 2005, 61, 1015. doi:10.1016/j.tet.2004.10.070

6. Pârvulescu, V. I.; Hardacre, C. Chem. Rev. 2007, 107, 2615. doi:10.1021/cr050948h

7. Aggarwal, A.; Lancaster, N. L.; Sethi, A. R.; Welton, T. Green Chem. 2002, 4, 517. doi:10.1039/b206472c

8. Vidiš, A.; Ohlin, C. A.; Laurenczy, G.; Küsters, E.; Sedelmeier, G.; Dyson, P. J. Adv. Synth. Catal. 2005, 347, 266. doi:10.1002/adsc.200404301

9. Tsuzuki, S.; Tokuda, H.; Mikami, M. Phys. Chem. Chem. Phys. 2007, 9, 4780. doi:10.1039/b707419k
10. Sereda, O.; Tabasum, S.; Wilhelm, R. Top. Curr. Chem. 2010, 291, 349. doi:10.1007/128_2008_17

See for a review.

11. Jurčík, V.; Wilhelm, R. Org. Biomol. Chem. 2005, 3, 239. doi:10.1039/b415023f

12. Jurčík, V.; Wilhelm, R. Tetrahedron: Asymmetry 2006, 17, 801. doi:10.1016/j.tetasy.2006.02.021

13. Mukaiyama, T.; Yanagisawa, M.; Iida, D.; Hachiya, I. Chem. Lett. 2000, 606. doi:10.1246/cl.2000.606

14. Chen, C.-T.; Chao, S.-D.; Yen, K.-C.; Chen, C. H.; Chou, I.-C.; Hon, S.-W. J. Am. Chem. Soc. 1997, 119, 11341. doi:10.1021/ja970900o

15. Chen, C.-T.; Chao, S.-D.; Yen, K.-C. Synlett 1998, 924. doi:10.1055/s-1998-1815

16. Dalko, P. I.; Moisan, L. Angew. Chem., Int. Ed. 2001, 40, 3726 doi:10.1002/1521-3773(20011015)40:20<3726::AID-ANIE3726>3.0.CO ;2-D See for a review.

17. Berkessel, A.; Gröger, H. Asymmetric Organocatalysis; Wiley-VCH: Weinheim, Germany, 2005. See for a review.

18. Wittkopp, A.; Schreiner, P. Chem.-Eur. J. 2003, 9, 407. doi:10.1002/chem.200390042

19. Lopez, P.; Oh, T. Tetrahedron Lett. 2000, 41, 2313. doi:10.1016/S0040-4039(00)00157-X

20. Oh, T.; Lopez, P.; Reilly, M. Eur. J. Org. Chem. 2000, 2901. doi:10.1002/1099-0690(200008)2000:16<2901::AID-EJOC2901>3.0.C $0 ; 2-0$

21. Lee, H.; Diaz, M.; Hawthorne, M. F. Tetrahedron Lett. 1999, 40, 7651. doi:10.1016/S0040-4039(99)01582-8

22. Alper, H.; Brandes, D. A. Organometallics 1991, 10, 2457. doi:10.1021/om00053a058

23. Wuest, J. D.; Zacharie, B. J. Am. Chem. Soc. 1985, 107, 6121. doi:10.1021/ja00307a058

24. Braddock, D. C.; Brown, J. M.; Guiry, P. J. J. Chem. Soc., Chem. Commun. 1993, 1244.

25. Clemens, N.; Sereda, O.; Wilhelm, R. Org. Biomol. Chem. 2006, 4, 2285. doi:10.1039/b601104g

26. Alder, R. W.; Blake, M. E.; Oliva, J. M. J. Phys. Chem. A 1999, 103, 11200. doi:10.1021/jp9934228

27. Magill, A. M.; Cavell, K. J.; Yates, B. F. J. Am. Chem. Soc. 2004, 126, 8717. doi:10.1021/ja038973x

28. Scarborough, C. C.; Popp, B. V.; Guzei, I. A.; Stahl, S. S. J. Organomet. Chem. 2005, 690, 6143. doi:10.1016/j.jorganchem.2005.08.022

29. Iglesias, M.; Beetstra, D. J.; Knight, J. C.; Ooi, L.-L.; Stasch, A.; Coles, S.; Male, L.; Hursthouse, M. B.; Cavell, K. J.; Dervisi, A.; Fallis, I. A. Organometallics 2008, 27, 3279. doi:10.1021/om800179t

30. Angelovski, G.; Keränen, M. D.; Eilbracht, P. Tetrahedron: Asymmetry 2005, 16, 1919. doi:10.1016/j.tetasy.2005.03.035 


\section{License and Terms}

This is an Open Access article under the terms of the Creative Commons Attribution License

(http://creativecommons.org/licenses/by/2.0), which permits unrestricted use, distribution, and reproduction in any medium, provided the original work is properly cited.

The license is subject to the Beilstein Journal of Organic Chemistry terms and conditions:

(http://www.beilstein-journals.org/bjoc)

The definitive version of this article is the electronic one which can be found at:

doi:10.3762/bjoc.8.205 